Marquette University

e-Publications@Marquette

$12-1-2015$

\title{
The Association of Dorsiflexion Flexibility on Knee Kinematics and Kinetics during a Drop Vertical Jump in Healthy Female Athletes
}

Philip Malloy

Marquette University, philip.malloy@marquette.edu

Alexander Morgan

Marquette University

Carolyn M. Meinerz

Marquette University

Christopher Geiser

Marquette University, christopher.geiser@marquette.edu

Kristof Kipp

Marquette University, kristof.kipp@marquette.edu

Accepted version. Knee Surgery, Sports Traumatology, Arthroscopy, Vol. 23, No. 12 (December 2015): 3550-3555. DOI. (C) 2015 Springer.Used with permission. 
Marquette University

e-Publications@Marquette

\section{Exercise Science Faculty Research and Publications/Department of Exercise Science}

This paper is NOT THE PUBLISHED VERSION; but the author's final, peer-reviewed manuscript. The published version may be accessed by following the link in the citation below.

Knee Surgery, Sports Traumatology, Arthoscopy, Vol. 23, No. 12 (December 2015): 3550-3555. DOI. This article is (C) Springer and permission has been granted for this version to appear in $\underline{\text { e- }}$ Publications@Marquette. Springer does not grant permission for this article to be further copied/distributed or hosted elsewhere without the express permission from Springer.

\section{The association of dorsiflexion flexibility on knee kinematics and kinetics during a drop vertical jump in healthy female athletes}

Philip Malloy

Department of Physical Therapy, Marquette University, Milwaukee, WI

Alexander Morgan

Department of Physical Therapy, Marquette University, Milwaukee, WI

Carolyn Meinerz

Department of Physical Therapy, Marquette University, Milwaukee, WI Christopher Geiser

Department of Physical Therapy, Marquette University, Milwaukee, WI Kristof Kipp

Department of Physical Therapy, Marquette University, Milwaukee, WI 


\section{Abstract \\ Purpose}

While previous studies have examined the association between ankle dorsiflexion flexibility and deleterious landing postures, it is not currently known how landing kinetics are influenced by ankle dorsiflexion flexibility. The purpose of this study was to examine whether ankle dorsiflexion flexibility was associated with landing kinematics and kinetics that have been shown to increase the risk of anterior cruciate ligament $(\mathrm{ACL})$ injury in female athletes.

\section{Methods}

Twenty-three female collegiate soccer players participated in a preseason screening that included the assessment of ankle dorsiflexion flexibility and lower-body kinematics and kinetics during a drop vertical jump task.

\section{Results}

The results demonstrated that females with less ankle dorsiflexion flexibility exhibited greater peak knee abduction moments ( $r=-.442)$, greater peak knee abduction angles $(r=.355)$, and less peak knee flexion angles $(r=.385)$ during landing. The range of dorsiflexion flexibility for the current study was between $9^{\circ}$ and $23^{\circ}$ (mean $\left.=15.0^{\circ} ; \mathrm{SD} 3.9^{\circ}\right)$.

\section{Conclusion}

Dorsiflexion flexibility may serve as a useful clinical measure to predict poor landing postures and external forces that have been associated with increased knee injury risk. Rehabilitation specialists can provide interventions aimed at improving dorsiflexion flexibility in order to ameliorate the impact of this modifiable factor on deleterious landing kinematics and kinetics in female athletes.

Level of evidence

II.

Keywords

ACL injury, Ankle flexibility, Kinematics, Kinetics, Landing mechanics

This study was approved by the Institutional Review Board at Marquette University.

Introduction

Female soccer players demonstrate a significantly greater incidence of anterior cruciate ligament $(A C L)$ injury compared with their male 
counterparts. ${ }^{1,3,10,12}$ The majority of these $A C L$ injuries occur through a noncontact mechanism. ${ }^{2}$ Direct observation using video analysis has identified a characteristic posture of the knee at the time of ACL injury that includes a position of near full extension, knee valgus, and tibial internal rotation. ${ }^{2,15}$ Cadaveric studies have demonstrated that in combination, these postures result in loading states that increase the strain on the ACL. ${ }^{19,22,25,29,30}$ Additionally, greater knee abduction moments, greater knee valgus angles, and reduced peak knee flexion angles during landing have been identified as risk factors for $A C L$ injury in female athletes. ${ }^{14}$ The information on $A C L$ injury mechanisms and risk factors has led to the development of neuromuscular training programs directed at modifying these dangerous landing mechanics. ${ }^{13,21,24}$ It is encouraging that these programs have shown some success at reducing incidence of $A C L$ injury; however, the overall incidence of ACL injury in female athletes remains high. ${ }^{1,16}$ Therefore, continued research is needed to identify modifiable factors that may be associated with poor landing mechanics that have been linked to an increased risk for ACL injury. Rehabilitation specialists commonly direct treatment interventions at modifiable factors such as flexibility, strength, and neuromuscular control; therefore, a greater understanding of the modifiable factors that influence landing kinematics and kinetics is warranted to help guide individualized treatment interventions for $\mathrm{ACL}$ injury prevention.

Among modifiable factors, a recent focus has been on flexibility of the ankle because it can be easily measured and improved through training interventions. $8,20,23,26,27$ Limitations in ankle dorsiflexion flexibility with the knee in an extended position have been linked to deleterious landing mechanics. ${ }^{8,27}$ Fong and colleagues showed that individuals with less ankle dorsiflexion flexibility landed with less knee flexion excursion during a drop vertical jump task. ${ }^{8}$ Another study demonstrated that a reduction in ankle range of motion was correlated with greater knee frontal plane excursion during the landing phase of a drop jump in female soccer players. ${ }^{27}$ Additionally, Bell and colleagues found that medial knee displacement while performing a squat was reduced by placing individuals on a decline board so that the ankle is in plantar flexion at the start of the movement thereby 
increasing the available ankle dorsiflexion range of motion during the movement. ${ }^{4}$

Although reduced ankle dorsiflexion flexibility has been linked to at risk landing kinematics, ${ }^{8,27}$ no studies have focused specifically on the association between knee joint kinetics and dorsiflexion flexibility. Therefore, investigation of the links between ankle flexibility and landing kinetics is needed because peak frontal plane abduction moments in particular have been associated with greater risk of ACL injury. ${ }^{14}$ The primary purpose of this investigation was to determine the association between ankle dorsiflexion flexibility and lower extremity kinetics and kinematics in female athletes during a drop vertical jump task. We hypothesized that reduced ankle dorsiflexion flexibility would be associated with greater peak knee abduction moments during landing. Additionally, we hypothesized that less dorsiflexion flexibility would be associated with smaller peak knee flexion angles and greater knee peak abduction angles during landing.

Materials and methods

Twenty-three female collegiate soccer players between the ages of 1821 years of age were recruited for a pre-season biomechanical injury screening. An a priori calculation for sample size demonstrated that a sample of 20 subjects was needed to explain at least $50 \%$ of the variance of the dependent variables using a two-tailed bivariate correlation model. ${ }^{7}$ The average \pm SD for age, height, and weight of the participants were $19.4 \pm .84$ years, $167.9 \pm 5.0 \mathrm{~cm}$, and $61.0 \pm 4.0 \mathrm{~kg}$, respectively. All subjects were healthy without musculoskeletal, neurologic, or cardiovascular conditions that would prevent them from fully participating in the testing protocol. A health history questionnaire was given to all athletes to determine whether injury occurred within the last year. If the athletes experienced a knee or ankle injury within the last year, they were excluded from the study. 
Ankle dorsiflexion flexibility measure

Ankle dorsiflexion flexibility was measured bilaterally using a standard longarm goniometer (Sammons Preston ${ }^{\mathrm{TM}}$ ). Ankle dorsiflexion measures were taken by one of two experienced licensed physical therapist/athletic trainers with 24 and 12 years of experience, respectively. The subjects assumed a long sitting position with the knee fully extended $\left(0^{\circ}\right)$ and the foot and ankle placed off the edge of a treatment table. The ankle joint was placed in a subtalar neutral position for the measurement. The axis of the goniometer was positioned in-line with the lateral malleolus and the stationary arm aligned with the shaft of the fibula. The moving arm consisted of an acrylic plate to maintain neutral alignment of the foot during the measure and was aligned with the fifth metatarsal. The subject was instructed to pull their foot toward their face moving at the ankle without bending the knee. Maximal active-assisted dorsiflexion flexibility was measured by applying overpressure to the foot plantar surface of the foot at the level of the metatarsal heads after the subject achieved maximal active range of motion. The end of ankle dorsiflexion flexibility was indicated by the end of available ankle range of motion as overpressure was applied; however, the amount of force was not quantified.

Drop jump task

Prior to testing, the box height for the drop vertical jump (DVJ) task was normalized by having each subject first perform five maximal effort vertical jumps from a standing position with each foot on an AMTI force plate (AMTI Corp. Watertown, MA). Vicon Nexus software 1.8.2 (Vicon Motion Systems Ltd.) was used to generate a plot based on the position of the right posterior superior iliac crest (PSIS) marker during the third trial of the maximum vertical jumps. The difference between the height of the marker position in standing and the position of the marker at peak jump height was used for the height of the box. The box height was normalized in this manner because this represents the typical height from which an individual would land from a jump during play as opposed to a standard box height, which has been previously described in the literature. ${ }^{14}$ Following this normalization procedure, each subject then performed ten DVJs. The 
directions for the drop vertical jump instructed subjects to move as if they were going to step off the box and drop directly onto the force plates. Immediately upon landing, the subjects then performed a maximum vertical jump. The subjects were explicitly instructed to not jump off of the box onto the plate.

\section{Data acquisition}

Three-dimensional (3D) motion data were collected as each subject performed the DVJ's through the use of fourteen Vicon infrared cameras (Vicon Motion Systems Ltd.). Raw marker position data were recorded using ViconNexus software 1.8.2 and processed with Visual 3D software (CMotion, Inc, Rockville, MD). The kinematic data were sampled at $120 \mathrm{~Hz}$. Twenty-three single retro-reflective markers were placed on the skin overlying the anatomical landmarks of C7 spinous process, T10 spinous processes, sternum, and bilaterally over the PSIS, ASIS, iliac crests, greater trochanters, medial and lateral knee joint lines, medial and lateral malleoli, and first and fifth metatarsal heads. Marker clusters consisting of four markers attached to a plastic plate fixed to a Velcro strap were used for the bilateral thighs and shanks. ${ }^{9}$ A cluster of three markers attached to a plastic plate was fixed directly to the bilateral heels using standard athletic tape. ${ }^{9} \mathrm{~A}$ static standing trial was performed prior to movement testing to individualize marker position and allow an accurate calculation of joint centers and segments positions for each individual subject during the testing. All individual markers were removed following the static trial with the exception of C7, T10, sternum, bilateral ASIS, and bilateral PSIS markers. Kinetic data were collected using two AMTI force plates (AMTI Corp. Watertown, MA). The force data were collected at $960 \mathrm{~Hz}$.

\section{Data processing}

A fourth-order, low- pass Butterworth filter with a cutoff frequency of $12 \mathrm{~Hz}$ was used to process the kinematic and kinetic data in Visual 3D. A local coordinate system was used to define the model segments for the pelvis, thigh, shank, and foot segments based on marker position over the anatomical landmarks of the proximal and distal aspects of the segment. A 
joint coordinate system approach was used to determine the angles of the hip, knee, and ankle. ${ }^{11}$ An inverse dynamics approach was used to calculate external joint moments using the ground reaction force (GRF) and kinematic data. External joint moments are normalized to body weight and were calculated from the angular acceleration of the distal relative to the proximal segment. The time series for the peak moment calculations were from initial contact, which was defined as the point at which the vertical ground reaction was $>30 \mathrm{~N}$, through peak knee flexion angle. The peak knee abduction moment reported were that of the peak during the landing phase and may have occurred prior to the point of peak knee flexion. For simplification, all data were presented from the perspective of a right lower extremity right hand rule. Peak knee flexion angles, peak knee abduction angles, peak knee abduction moments, and peak vertical ground reaction forces (vGRF) were calculated during the landing phase. Means and standard deviations of these variables were calculated and used for analysis. Prior to the participation in the study all of the testing procedures were explained, and informed consent was obtained as approved by the Institutional Review Board of Marquette University IRB protocol \# HR-2437.

\section{Statistical analysis}

Statistical analyses were performed using SPSS version 20.0 (SPSS, Inc, Chicago, IL). Pearson's correlations were calculated to determine the associations between the independent variable (ankle dorsiflexion flexibility) and each of the four dependent variables (peak knee flexion, peak knee abduction, peak knee abduction moment, and vertical ground reaction forces). Statistical significance was set a priori at $\alpha=.05$.

\section{Results}

The range of dorsiflexion flexibility for the sample were between $9^{\circ}$ and $23^{\circ}$ $\left(\right.$ mean $=15.0^{\circ} ;$ SD $\left.3.9^{\circ}\right)$. A significant negative correlation was found between ankle dorsiflexion flexibility and peak external knee abduction moment (Fig. 1; $r=-.442, p=.017$ ). Females with less ankle dorsiflexion flexibility demonstrated greater peak external knee abduction moments during the defined landing phase of the drop vertical jump task. 
Significant positive correlations were found between ankle dorsiflexion flexibility and peak knee flexion angle (Fig. $2 ; r=.385, p=.035$ ) and peak knee abduction angle (Fig. $3 ; r=.355, p=.048$ ). No significant correlations were found between ankle dorsiflexion flexibility and vertical ground reaction forces.

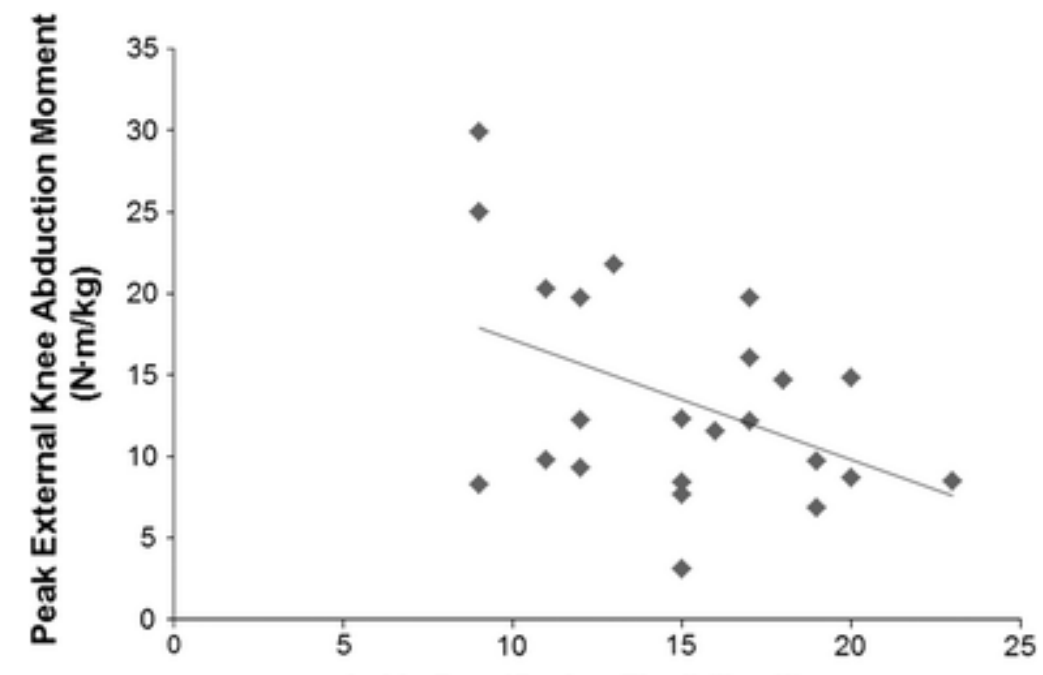

Fig. 1

Ankle Dorsiflexion Flexibility $\left({ }^{\circ}\right)$

Peak external knee abduction moments as a function of ankle dorsiflexion flexibility in female athletes during a drop vertical jump task. The mean maximal external knee abduction moment of the ten trials performed is represented for each participant $(\mathrm{N} \mathrm{m} / \mathrm{kg})$

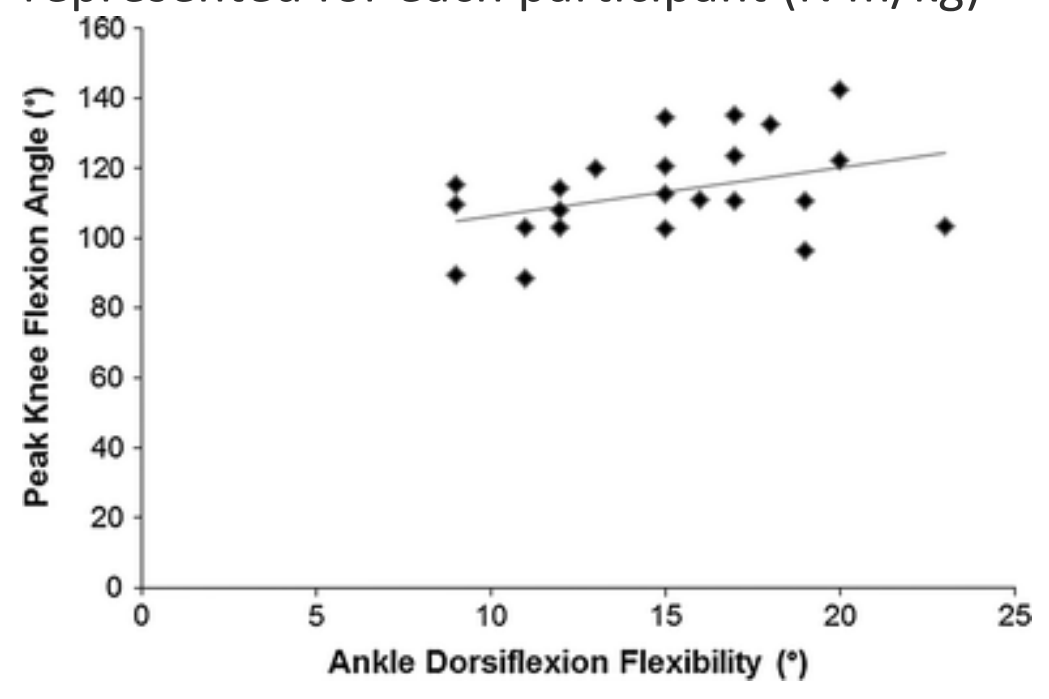


Fig. 2

Peak knee flexion angle as a function of ankle dorsiflexion flexibility in female athletes during a drop vertical jump task. The mean maximum knee flexion angle for the ten trials is represented for each participant $\left({ }^{\circ}\right)$

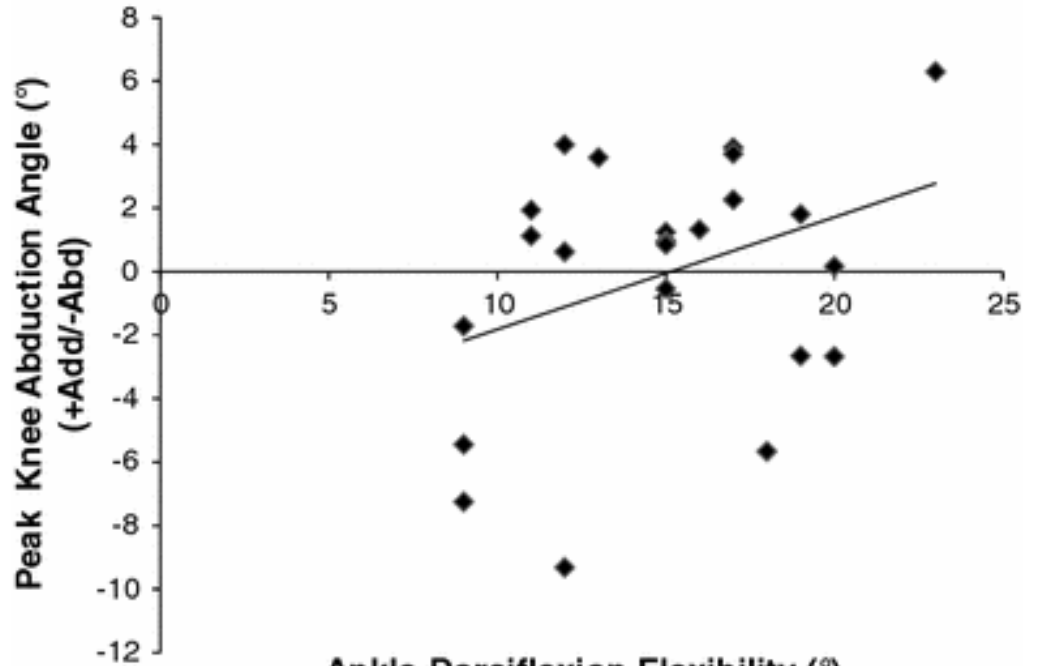

Ankle Dorsiflexion Flexibility ( $\left.{ }^{\circ}\right)$

\section{Fig. 3}

The mean maximal knee abduction angle as a function of ankle dorsiflexion flexibility in female athletes during a drop vertical jump task. The mean maximum knee abduction angle for the ten trials is represented for each participant $\left({ }^{\circ}\right)$. Negative values represent knee abduction

\section{Discussion}

The purpose of this investigation was to determine the association between ankle dorsiflexion flexibility and lower extremity kinetics and kinematics during a drop vertical jump task in female athletes. The most important result from this study was the association between less ankle dorsiflexion flexibility and greater peak external knee abduction moments during landing. Our results also showed that less ankle dorsiflexion flexibility was associated with greater peak knee abduction angles, and lower peak knee flexion angles. These results support both of our hypotheses. Although the statistical magnitude of the correlation between ankle dorsiflexion flexibility and knee abduction moments was moderate, to our knowledge, this is the first investigation to demonstrate such findings. These results are, however, of clinical importance because greater peak knee abduction moments have 
been prospectively linked to a greater risk of ACL injury in female athletes. ${ }^{14}$ Interestingly, the results from the current study indicated that there was no relationship between ankle dorsiflexion flexibility and ground reaction forces. While this result is contrary to previous findings, ${ }^{8}$ recent research suggests that external knee abduction moments are driven more by the moment arm of the vGRF than its magnitude. ${ }^{22}$ The link between ankle dorsiflexion flexibility and knee kinetics may therefore lie in the postures of the lower extremity during landing as reflected by the kinematic findings of the current study.

Our results indicated a positive association between peak knee abduction angle and dorsiflexion flexibility suggesting that females with less ankle dorsiflexion flexibility exhibit greater peak abduction angles during landing. This kinematic finding is similar to that of Sigward and colleagues ${ }^{27}$ who found that less ankle dorsiflexion range of motion was associated with greater frontal plane knee excursion in female soccer players during a drop jump task. Although our study examined peak knee abduction angles, as opposed to frontal plane excursion measured by Sigward, ${ }^{27}$ both investigations linked reduced dorsiflexion flexibility to knee frontal plane kinematics. Limitations in available dorsiflexion motion have also been linked to greater medial knee displacement and peak knee valgus angle during squatting tasks, which also lends support for a link between ankle dorsiflexion flexibility and frontal plane knee kinematics. ${ }^{20,23}$ It could be hypothesized that the link between gastrocnemius tightness and aberrant frontal plane kinematics is the result of limited forward excursion of the tibia over the talus during closed chain tasks. Reduced flexibility may result in compensatory frontal plane motion at more proximal joints so as to accommodate for the lack of sagittal plane motion at the ankle. This hypothesis is supported by the work of Maunte ${ }^{23}$ that showed that medial knee displacement (i.e., knee valgus) during a single leg squat was influenced more so by gastrocnemius/soleus flexibility as opposed to a restriction in posterior talar motion, which could also limit ankle dorsiflexion. Another potential contribution to greater knee abduction angle may have been related to the foot position during landing, as this has been shown to contribute to the dynamic valgus posture at the knee. ${ }^{17}$ 
Collectively these studies provide a link between dorsiflexion flexibility and knee kinematics. The current findings extend this link to include a relationship between dorsiflexion flexibility and knee joint kinetics because these greater peak abduction angles would create a larger moment arm between the ground reaction force and the knee joint center in the frontal plane. ${ }^{18}$

The current study also found that females with less dorsiflexion flexibility exhibited less peak knee flexion during landing. This finding is consistent with research by Fong and colleagues ${ }^{8}$ who reported that less dorsiflexion flexibility was associated with less knee flexion excursion between initial ground contact and peak knee flexion during landing. Another consistent finding between the two investigations was the lack of a significant association between dorsiflexion flexibility and ankle kinematics during landing. ${ }^{8}$ Given that the ankle is typically in a plantar-flexed position at initial contact to dissipate ground reaction forces, the total amount of ankle joint excursion during the landing phase may simply be related to the adopted ankle landing strategy of the individual, which would then explain the lack of association between dorsiflexion flexibility and sagittal plane ankle kinematics. The mean ankle dorsiflexion flexibility of subjects in the current study and that of Fong's were also similar $\left(15.0^{\circ}\right.$ vs. $\left.14.3^{\circ}\right) .^{8}$

Although the correlations in the current study were statistically significant, the magnitudes of the correlations were low to moderate. However, when the correlations are considered in combination, one could speculate that a scenario of greater ACL loading may occur because each of the correlations and the corresponding kinematic postures are linked to $A C L$ injury risk. Cadaveric investigations using simulated landing tasks in similar postures observed in this study demonstrate knee loading conditions with greater strain borne across the ACL. ${ }^{19,22,25,29,30}$ Specifically, knee abduction has been shown to significantly contribute to ACL strain at the time of failure. ${ }^{19}$ Therefore, our findings that link ankle dorsiflexion flexibility with biomechanical variables that are associated with the risk of ACL injury provides important information on the potential contribution of modifiable factors to deleterious landing kinematics and kinetics. These findings are 
meaningful to clinicians in the context of the $A C L$ injury mechanism because ankle dorsiflexion flexibility measures combined with other clinical data may assist rehabilitation specialists in developing screening measures and neuromuscular training programs to ameliorate dangerous joint loading scenarios. Interestingly, a recent systematic review on the effectiveness of neuromuscular training programs aimed at reducing $A C L$ injury in females athletes found that 2 of the 3 programs that reduced $A C L$ injury incidence did involve a flexibility component. ${ }^{28}$ Nonetheless, controlled interventional studies are needed that are directed at improving modifiable injury risk in females that demonstrate potentially dangerous landing kinematics and kinetics.

There are several limitations to the current study that must be considered. The amount of pressure exerted by the examiner was not standardized using a force measurement device during dorsiflexion flexibility measurements. Another limitation of the study was that dorsiflexion flexibility was not measured with the knee in a flexed position to evaluate the soleus muscle, which can also contribute to a loss of dorsiflexion flexibility. Another potential limitation is that screening included a history of injury that limited participation in the previous season, a complete history regarding previous ankle injury was not reported. Alterations in kinematics and kinetics of the lower extremity have been found in individuals' ankle instability. ${ }^{5,6}$ Further, associations between ankle dorsiflexion flexibility and landing mechanics are limited to cross-sectional studies, and the impact of improving ankle dorsiflexion flexibility on landing mechanics is not known. Additional research (i.e., longitudinal studies) is needed to determine whether an improvement in ankle dorsiflexion flexibility ameliorates deleterious landing mechanics. Despite the limitations, the findings of the current study are useful to rehabilitation specialists because reduced dorsiflexion may influence dangerous knee kinematics and kinetics during landing. Clinicians should assess dorsiflexion flexibility in athletes and direct intervention as necessary to improve flexibility if deficits are demonstrated. 
The current study demonstrated that the landing kinematics and kinetics of female athletes with reduced ankle dorsiflexion flexibility were characterized by greater peak knee abduction moments and angles, and reduced peak knee flexion angles. Ankle dorsiflexion flexibility may therefore represent a modifiable factor that can be targeted through stretching exercises aimed at the plantar flexors. The association between ankle dorsiflexion flexibility and knee kinetics and kinematics are important because this clinical measure could be easily assessed during pre-season screening and improved through stretching and mobility treatment interventions.

\section{Notes}

\section{Acknowledgments}

The authors would like to acknowledge support through the National Center for Advancing Translational Sciences, National Institutes of Health, Grant Number 8UL1TR000055.

\section{Conflict of interest}

No disclosures or conflicts of interest to report.

\section{References}

${ }^{1}$ Agel J, Klossner D (2014) Epidemiologic review of collegiate ACL injury rates across 14 sports: National Collegiate Athletic Association injury surveillance system data 2004-2005 through 2011-2012. Br J Sports Med 48:560

${ }^{2}$ Alentorn-Geli E, Myer GD, Silvers HJ, Samitier G, Romero D et al (2009) Prevention of non-contact anterior cruciate ligament injuries in soccer players: part 1: mechanisms of injury and underlying risk factors. Knee Surg Sports Traumatol Arthrosc 17: 705-729

${ }^{3}$ Arendt E, Dick R (1995) Knee injury patterns among men and women in collegiate basketball and soccer: NCAA data and review literature. Am J Sports Med 23:694-701

${ }^{4}$ Bell DR, Padua DA, Clark MA (2008) Muscle strength and flexibility characteristics of people displaying medial knee displacement. Arch Phys Med Rehab 89:1323-1328

${ }^{5}$ Caulfield B, Garrett M (2004) Changes in ground reaction force during jumping in subjects with functional instability of the ankle joint. Clin Biomech 19:617-621

${ }^{6}$ Delahunt E, Monaghan K, Caulfild B (2006) Changes in lower limb kinematics, kinetics, and muscle activity in subjects with functional instability of the ankle joints during a single leg drop jump. J Orthop Res 24:1991-2000

${ }^{7}$ Faul F, Erdefelder E, Buchner A, Lang AG (2009) Statistical power analysis using G*Power 3.1: tests for correlation and regression analyses. Behav Res Methods 41:1149-1160

${ }^{8}$ Fong C, Blackburn JT, Norcross MF, McGrath M, Padua DA (2011) Ankle-dorsiflexion range of motion and landing biomechanics. J Athl Train 46:5-10 
${ }^{9}$ Geiser CF, O'Connor KM, Earl JE (2010) Effects of isolated hip abductor fatigue on frontal plane knee mechanics. Med Sci Sports Exerc 42:535-545

10. Griffin LY, Albohm MJ, Arendt EA et al (2006) Understanding and preventing noncontact anterior cruciate ligament injuries: a review of the Hunt Valley meeting, January 2005. Am J Sports Med 34:1512-1532

11.Grood ES, Suntay WJ (1983) A joint coordinate system for the clinical description of three-dimensional motions: application to the knee. J Biomech Eng 105:136-144

12. Gwinn DE, Wilckens JH, McDevitt ER, Ross G, Kao T (2000) The relative incidence of anterior cruciate ligament injury in men and women at the United States Naval Academy. Am J Sports Med 28:98-102

13. Hewett TE, Lindenfeld TN, Riccobene JV, Noyes FR (1999) The effect of neuromuscular training and the incidence of knee injury in female athletes: a prospective study. Am J Sports Med 27:699-706

14. Hewett TE, Myer GD, Ford KR et al (2005) Biomechanical measures of neuromuscular control and valgus loading of the knee predict anterior cruciate injury risk in female athletes: a prospective study. Am J Sports Med 33:492-501

15. Hewett TE, Torg JS, Boden BP (2009) Video analysis of trunk and knee motion during non-contact anterior cruciate ligament injury in female athletes: lateral trunk and knee abduction motion are combined components of the injury mechanism. Br J Sports Med 43:417-422

16. Hootman JM, Dick R, Agel J (2007) Epidemiology of collegiate injuries for 15 sports: summary and recommendations for injury prevention initiatives. J Athl Train 42:311-319

17. Ishida T, Yamanaka M, Takeda N, Aoki Y (2014) Knee rotation associated with dynamic knee valgus and toe direction. Knee 21:563-566

18. Kristianslund E, Faul O, Myklebust G, Krosshaug T (2014) Sidestep cutting technique and knee abduction loading: implications for ACL prevention exercises. Br J Sports Med 48:779-783

19. Levine JW, Kiapour AM, Quatman CE, Wordeman SC, Goel VK, Hewett TE, Demetropoulus CK (2013) Clinically relevant injury patterns after an anterior cruciate ligament injury provide insight into injury mechanisms. Am J Sports Med 41:385-395

20. Macrum E, Bell DR, Boling M, Lewek M, Padua D (2012) Effect of limiting ankle-dorsifleixon range of motion on lower extremity kinematics and muscle activation patterns during a squat. J Sports Rehabil 21:144-150

${ }^{21}$. Mandelbaum BR, Silvers HJ, Watanabe DS et al (2005) Effectiveness of a neuromuscular and proprioceptive training program in preventing anterior cruciate ligament injuries in female athletes: 2-year follow up. Am J Sports Med 33:1003-1010

22. Markolf KL, Burchfield DM, Shapiro MM, Shepard MF, Finerman GAM, Slauterbeck JL (1995) Combined knee loading states that generate high anterior cruciate ligament forces. J Orthop Res 13:930-935

${ }^{23 .}$ Mauntel TC, Begalle RL, Cram TR, Frank BS, Hirth CJ, Blackburn T, Padua DA (2013) The effects of lower extremity muscle activation and passive range of motion on single leg squat performance. J Strength Cond Res 27:1813-1823

24. Myklebust G, Engebretsen L, Braekken IH, Skjolberg A, Olsen OE, Bahr R (2003) Prevention of anterior cruciate ligament injuries in female team handball players: a prospective intervention study over three seasons. Clin J Sports Med 13:71-78

25. Quatman CCE, Kiapour AM, Demetrropoulus CK, Kiapour A, Wordeman SC, Levine JW, Goel VK, Hewett TE (2014) Preferential loading of the ACL compared with the MCL during landing: a novel sim approach yields multiplanar mechanisms of dynamic valgus during ACL injury. Am J Sports Med 42:177-186

26. Padua DA, Bell DR, Clark MA (2012) Neuromuscular characteristics of individuals displaying excessive medial knee displacement. J Athl Train 47:525-536

27. Sigward SM, Ota S, Powers CM (2008) Predictors of frontal plane knee excursion during a drop land in young female soccer players. J Orthop Sports Phys Ther 38:661-667

28.Stevenson JH, Beattie CS, Schwartz JB, Busconi BD (2014) Assessing the effectiveness of neuromuscular training programs in reducing the incidence of anterior cruciate ligament injuries in female athletes: a systematic review. Am J Sports Med. doi: 10.1177/0363546514523388

${ }^{29}$ Withrow TJ, Huston LJ, Wojyts EM, Ashton-Miller JA (2006) The effect of an impulsive knee valgus moment on in vitro relative $A C L$ strain during a simulated landing task. Clin Biomech 21:977-983 
30.Withrow TJ, Huston LJ, Wojyts EM, Ashton-Miller JA (2006) The relationship between quadriceps muscle force, knee flexion, and anterior cruciate ligament strain in an in vitro simulated jump landing. Am J Sports Med 34:269-274 